\title{
To Enhance Performance of Light Soaking Process on $\mathrm{ZnS} / \mathrm{CuIn}_{1-x} \mathrm{Ga}_{x} \mathrm{Se}_{2}$ Solar Cell
}

\author{
Yu-Jen Hsiao, ${ }^{1}$ Chung-Hsin Lu, ${ }^{2}$ and Te-Hua Fang ${ }^{3}$ \\ ${ }^{1}$ National Nano Device Laboratories, Tainan 741, Taiwan \\ ${ }^{2}$ Department of Chemical Engineering, National Taiwan University, Taipei 617, Taiwan \\ ${ }^{3}$ Department of Mechanical Engineering, National Kaohsiung University of Applied Sciences, Kaohsiung 807, Taiwan \\ Correspondence should be addressed to Yu-Jen Hsiao; yujenhsiao.tw@gmail.com
}

Received 20 September 2013; Accepted 13 October 2013

Academic Editor: Teen-Hang Meen

Copyright (C) 2013 Yu-Jen Hsiao et al. This is an open access article distributed under the Creative Commons Attribution License, which permits unrestricted use, distribution, and reproduction in any medium, provided the original work is properly cited.

\begin{abstract}
The $\mathrm{ZnS} / \mathrm{CuInGaSe}{ }_{2}$ heterojunction solar cell fabricated on Mo coated glass is studied. The crystallinity of the CIGS absorber layer is prepared by coevaporated method and the $\mathrm{ZnS}$ buffer layer with a band gap of $3.21 \mathrm{eV}$. The $\mathrm{MoS}_{2}$ phase was also found in the CuInGaSe 2 /Mo system form HRTEM. The light soaking effect of photoactive film for 10 min results in an increase in F.F. from 55.8 to $64 \%$, but series resistivity from 7.4 to $3.8 \Omega$. The efficiency of the devices improved from 8.12 to $9.50 \%$.
\end{abstract}

\section{Introduction}

Various photovoltaic (PV) devices have received a lot of attention as a renewable energy source [1]. These devices are made based on inorganic or organic materials, such as silicon-based thin film solar cells [2], multijunction solar cells [3], and dye-sensitized solar cells [4]. However, most of these devices suffer from either high cost or relatively low energy conversion efficiency. $\mathrm{CuIn}_{1-x} \mathrm{Ga}_{x} \mathrm{Se}_{2}$ (CIGS)-based thin films have received considerable attention as one of the most promising materials for thin film solar cells due to their high absorption coefficient, the potential for low cost manufacturing, and high conversion efficiency for inorganic solar cell application, although $\mathrm{Mo} / \mathrm{CuInGaSe}_{2}$ (CIGS) thin film solar cells have been extensively studied [5].

A high efficiency CIGS is usually fabricated by a coevaporation method, but this is a complex process to scale up to large areas due to the problem of nonuniformity. Several low cost and promising alternatives to coevaporation suitable for large scale production, such as sputtering [6], electrodeposition [7], and screen printing [8], have been investigated. In particular, sputtering of CuInGa precursors followed by selenization appears to be a favored process for thin film deposition [9]. In this study, a three-stage co-evaporation deposition technology was adopted to grow CIGS photovoltaic/electronic films to realize efficient solar cells. To avoid the Cd-induced pollution to environment, the n-type ZnS buffer layer for forming CIGS PVs was introduced [10].

In this paper, we report $\mathrm{ZnS} / \mathrm{CuIn}{ }_{1-x} \mathrm{Ga}_{x} \mathrm{Se}_{2}$ heterojunction solar cells fabricated on Mo coated glass. The crystallinity of the CIGS and ZnS buffer layer were studied. The microstructure phase was investigated in the $\mathrm{CuInGaSe}_{2} / \mathrm{Mo}$ system by HRTEM. The light soaking and electrical properties of the fabricated $\mathrm{p}$-CIGS/n-ZnS solar cells will also be discussed.

\section{Experimental}

The soda-lime glasses were carefully cleaned in isopropanolacetone ultrasonic bath to remove electrostatic charges. An approximately $0.7 \mu \mathrm{m}$ thick Mo back contact was directly deposited by RF sputtering on glass substrate. CIGS absorber layers were deposited by evaporation of elemental $\mathrm{Cu}, \mathrm{In}, \mathrm{Ga}$, and Se onto Mo by three-stage co-evaporation. During the 1st stage of the absorber growth the substrate temperature was kept at $400^{\circ} \mathrm{C}$, while during the 2 nd and 3 rd stages 
the substrate temperature increased up to $600^{\circ} \mathrm{C}$. The $100-$ $300 \mathrm{~nm}$ thick ZnS buffer layer was deposited on CIGS film by chemical bath deposition at $80^{\circ} \mathrm{C}$. The solar cells were finished by deposition of a $\mathrm{ZnS}$ buffer layer, RF sputtering of $\mathrm{ZnO}: \mathrm{Al}$ front contacts ( $400 \mathrm{~nm}$ thick), and electron beam evaporation of $1 \mu \mathrm{m}$ thick Al contact grids for better current collection. No antireflection (AR) coating was applied.

The phase identification was performed by X-ray powder diffraction (XRD, Rigaku Dmax-33). The surface microstructure was examined by scanning electron microscopy (SEM, Hitachi S4200). The morphology and microstructure were examined by transmission electron microscopy (HRTEM, HF-2000, Hitachi). The absorption spectra were obtained using an optical spectrometer (Hitachi, U-4100), and currentvoltage measurements (Keithley 2410 SourceMeter) were obtained using a solar simulator (TELTEC) with an AM 1.5 filter under an irradiation intensity of $100 \mathrm{~mW} / \mathrm{cm}^{2}$.

\section{Results and Discussion}

The CIGS quaternary alloy absorber layer coevaporated exhibits the characteristic peaks of chalcopyrite structure in $\mathrm{X}$-ray diffraction (XRD) analysis, as shown in Figure 1(a). XRD spectra also indicate that the CIGS film presents a strong (112) preferred orientation at $2 \theta=26.68$ corresponding to chalcopyrite phases. The other prominent peaks corresponded to the (220) and (312) directions. The full width at half maximum (FWHM) of the diffraction peak is rather small, which indicates that the film crystallinity is fairly good.

XRD patterns of $\mathrm{ZnS}$ with various deposition thicknesses are shown in Figure 1(b). The possible chemical reactions for the synthesis of $\mathrm{ZnS}$ films are as follows:

$$
\begin{gathered}
{\left[\mathrm{Zn}\left(\mathrm{H}_{2} \mathrm{O}\right)_{5}(\mathrm{OH})\right]^{+}+\mathrm{H}^{+} \longleftrightarrow \mathrm{Zn}(\mathrm{OH})_{2}+2 \mathrm{H}^{+}} \\
\mathrm{CH}_{3} \mathrm{CSNH}_{2}+\mathrm{H}^{+}+2 \mathrm{H}_{2} \mathrm{O} \\
\longleftrightarrow \mathrm{H}_{2} \mathrm{~S}+\mathrm{CH}_{3} \mathrm{COOH}+\mathrm{NH}_{4}^{+} \\
\mathrm{H}_{2} \mathrm{~S} \longleftrightarrow \mathrm{HS}^{-}+\mathrm{H}^{+} \longleftrightarrow \mathrm{S}^{2-}+\mathrm{H}^{+} \\
\mathrm{Zn}^{2+}+\mathrm{S}^{2-} \longrightarrow \mathrm{ZnS}
\end{gathered}
$$

During the reaction processes, sulfide ions are released slowly from $\mathrm{CH}_{3} \mathrm{CSNH}_{2}$ and react with zinc ions. It indicates that $\mathrm{ZnS}$ is produced by reaction of $\mathrm{S}^{2-}$ and $\mathrm{Zn}^{2+}$ in (4). All of the peaks were identified to be those of the cubic $\mathrm{ZnS}$ phase (JCPDS card number 79-0043) [11]. The crystallinity of $\mathrm{ZnS}$ increased along with deposition thickness. When the thickness was increased from 100 to $300 \mathrm{~nm}$, the peaks of (111), (220), and (311) were obviously shown.

Figure 2(a) has shown the UV-vis absorption spectra of $200 \mathrm{~nm}$ ZnS film on glass and estimated the band gap. For a direct band gap semiconductor, the absorbance in the vicinity of the onset due to the electronic transition is given by the following equation:

$$
\alpha=\frac{C\left(h v-E_{g}\right)^{1 / 2}}{h v},
$$

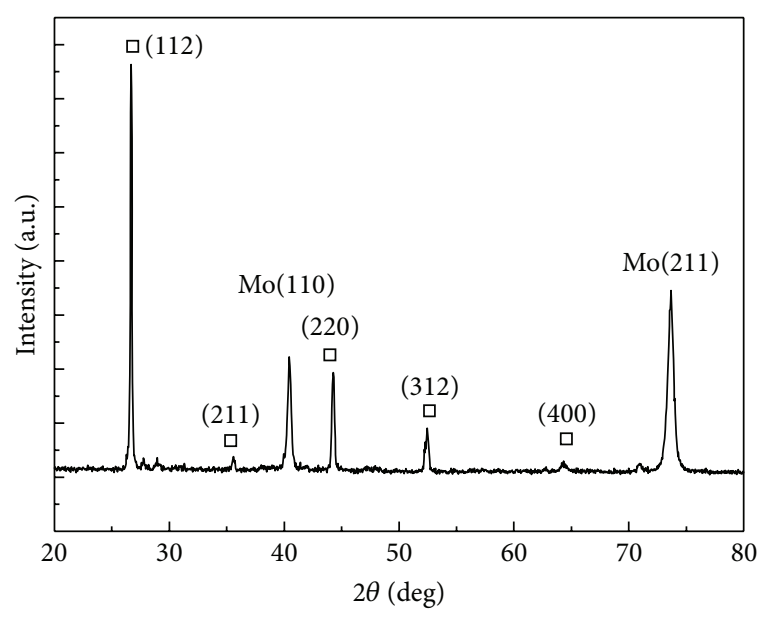

$\square$ CIGS film

(a)

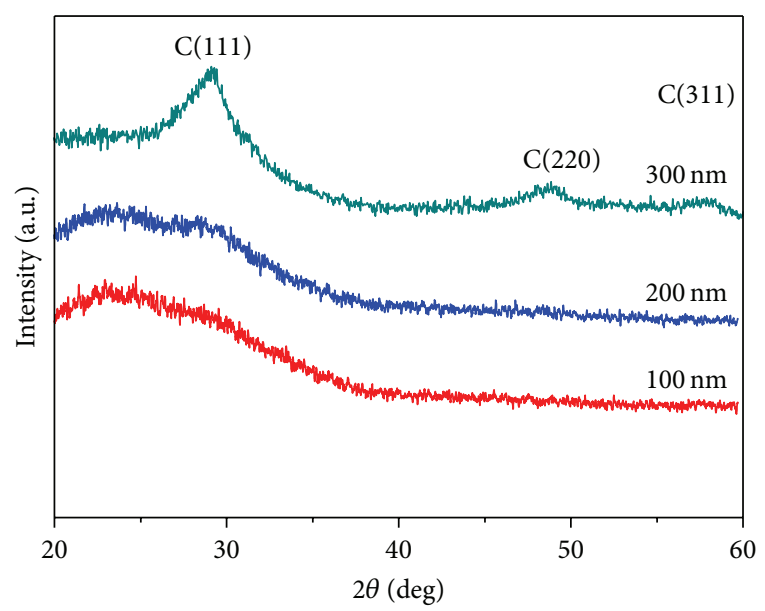

(b)

FIGURE 1: (a) XRD spectra of CIGS film on Mo electrode. (b) XRD spectra of ZnS film synthesized using a chemical bath deposition method at various thicknesses.

where $\alpha$ is the absorption coefficient, $C$ is the constant, $h v$ is the photon energy, and $E_{g}$ is the band gap. The visible light absorption edge of $200 \mathrm{~nm} \mathrm{ZnS} \mathrm{film} \mathrm{was} \mathrm{at} 386 \mathrm{~nm}$. Extrapolation of the linear region gives a band gap of $3.21 \mathrm{eV}$. Therefore, the direct band gap energy obtained from our experiment is $3.21 \mathrm{eV}$. As known, hydrothermal process may transform some elemental S species to sulfur dioxides. It has defect states like $\mathrm{S}$ vacancies in the band gap of $\mathrm{ZnS}$ [12]. Therefore, the sample had lower band gap than ideal crystal structure of $\mathrm{ZnS}$ with $3.68 \mathrm{eV}$. It has shown actual sample of $\mathrm{ZnS}$ film before and after being deposited on CIGS/Mo substrate in Figure 2(b). The color of CIGS/Mo was gray on the surface, and then we can see brown color as $\mathrm{ZnS}$ film deposited on CIGS/Mo substrate. Therefore, we can determine $\mathrm{ZnS}$ film on CIGS by color variability.

Figure 3(a) shows the cross-sectional bright field TEM image of the Mo/CIGS/ZnS stacked layers. In contrast to the relatively large grains of the CIGS layer $(0.2$ to $0.7 \mu \mathrm{m})$, 


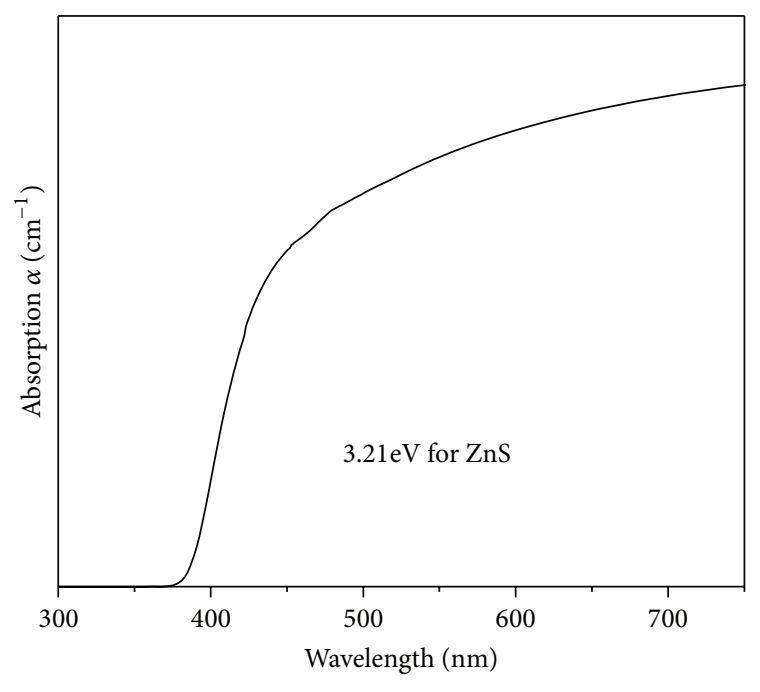

(a)

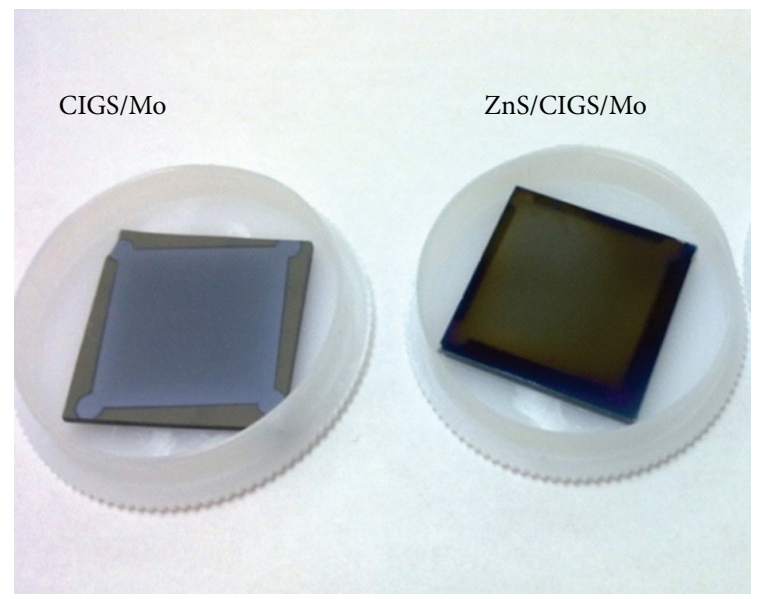

(b)

FIgURE 2: (a) Absorption spectra are as the function of photon energy for the $200 \mathrm{~nm} \mathrm{ZnS}$ film. (b) Realized sample of ZnS film deposited on CIGS/Mo substrate.

the ZnS layer consists of very small grains. Although the CIGS layer exhibits substantial surface roughness $(\sim 80 \mathrm{~nm}$ in average), the $\mathrm{ZnS}$ layer grown on top of CIGS has a uniform thickness $(\sim 200 \mathrm{~nm})$ that was prepared for TEM by the focused ion beam (FIB). Each one of the layers constituting the Mo/CIGS/ZnS system was investigated in order to know the formation of defects as well as to get information regarding crystalline structure and grain size. On the other hand, two different regions are identified in the $\mathrm{ZnS}$ and CIGS/Mo films as is observed in the micrograph of Figures 3(b)-3(c). The crystalline ZnS films are identified by the high resolution lattice images. A representative HRTEM image enlarging a round part of the structure in Figure 3(b) is given. The interplanar distances of the crystal fringes are about $0.31 \mathrm{~nm}$.

The microstructure of the Mo/CuInGaSe ${ }_{2}$ interfaces was investigated in order to visualize defects and the formation

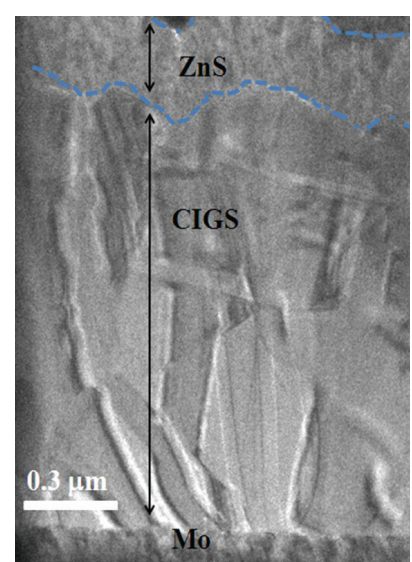

(a)

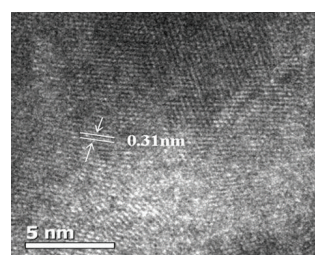

(b)

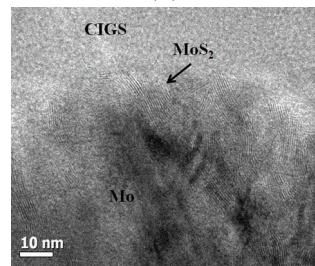

(c)
FigURE 3: (a) TEM cross-section images of ZnS/CIGS/Mo, (b) highresolution TEM image of the cubic $\mathrm{ZnS}$ film, and (c) the interface of CIGS and Mo.

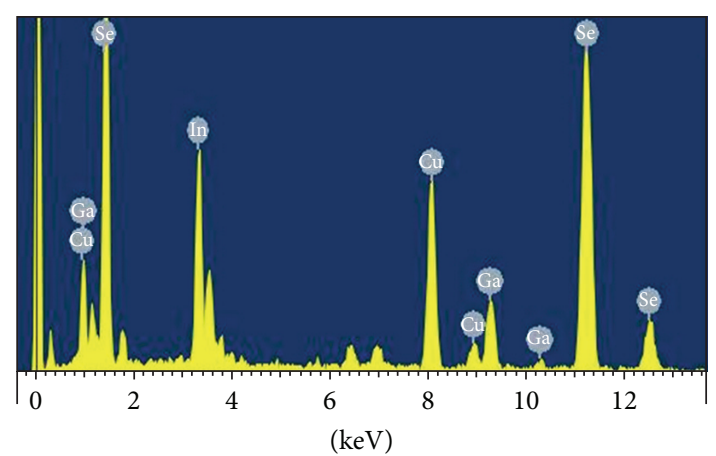

FIGURE 4: EDX analysis of the CIGS film.

of secondary phases as a result of possible chemical reactions occurring during the deposition of the stacked layers. Figure 3(c) shows a typical cross-sectional HRTEM image of the Mo/CIGS interface. The formation of a very thin layer $(10-40 \mathrm{~nm})$ of a new compound is observed around the Mo/CIGS interface. It seems that the new compound corresponds to the $\mathrm{MoS}_{2}$ phase due to the similarity with the CuInGaSe 2 /Mo system in which an interlayer of $\mathrm{MoSe}_{2}$ is usually formed [13]. This result makes sure that the metallic Mo thin layer is converted into $\mathrm{MoS}_{2}$ during the initial minutes of CIGS deposition. The $\mathrm{MoS}_{2}$ layer gives rise to a small conduction band offset with respect to the CIGS bulk material and a small Schottky barrier at the Mo back contact [14]. Both features are good for device performance, because the conduction band offset diminishes the back surface recombination, and then arrow Schottky barrier gives no substantial resistance to holes between CIGS and the metallic back contact. The EDS line profiles indicate that the CIGS film consists of $\mathrm{Cu}, \mathrm{In}, \mathrm{Ga}$, and $\mathrm{Se}$, as shown in Figure 4. In addition, the atomic concentrations of $\mathrm{Cu}=23 \%$, In = $21 \%, \mathrm{Ga}=10 \%$, and $\mathrm{Se}=46 \%$ are calculated from the EDS spectrum. 


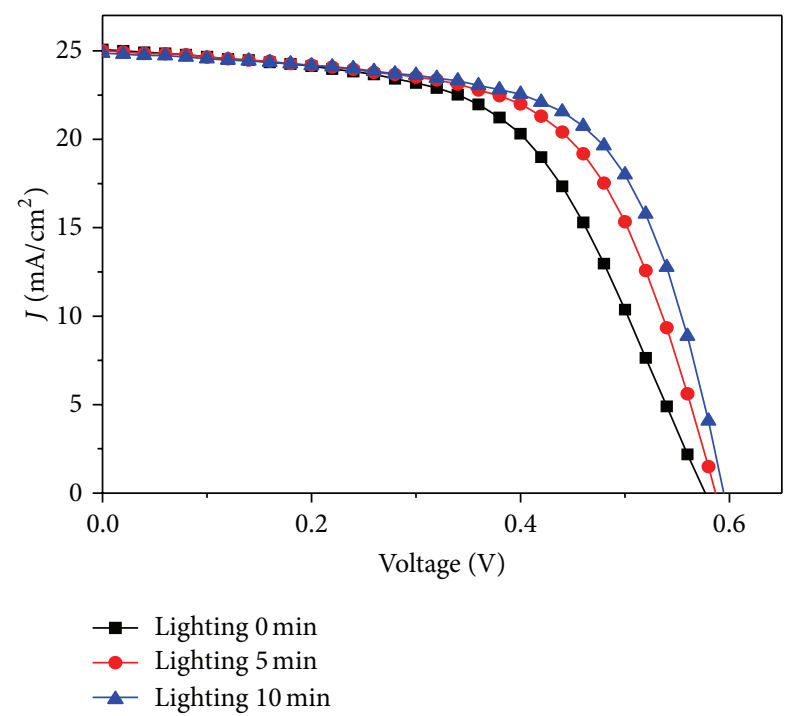

(a)

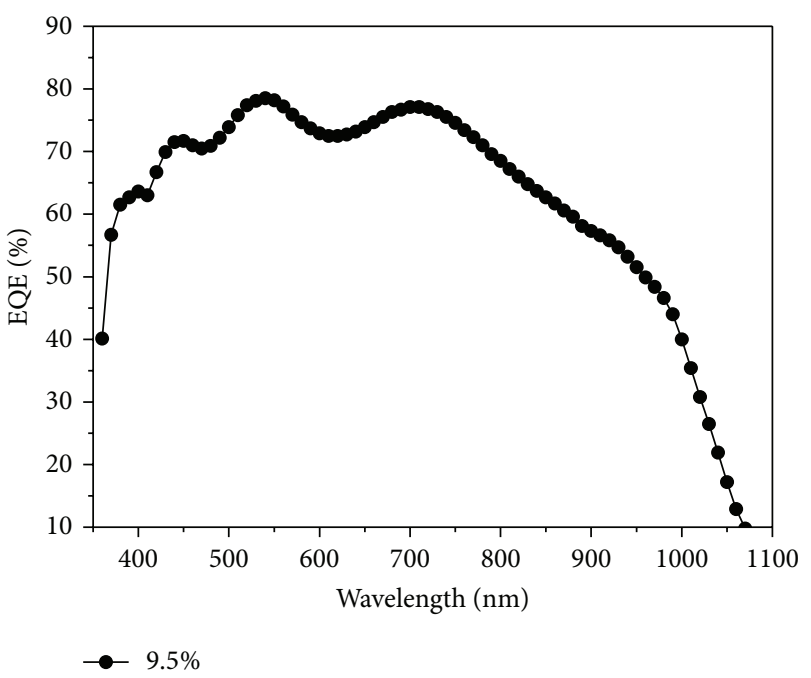

(b)

Figure 5: (a) $J$ - $V$ characteristics of ZnS/CIGS heterojunction solar cell with various light soaking times and (b) the IPCE spectrum of CIGS solar cell with efficiency of 9.5\%.

TABLE 1: Photovoltaic performance of the AZO/ZnS/CIGS heterojunction solar cell with various light soaking times, under AM1.5G at $100 \mathrm{~mW} / \mathrm{cm}^{2}$ illumination.

\begin{tabular}{lcccccc}
\hline $\begin{array}{l}\text { Light } \\
\text { soaking }\end{array}$ & $V_{\mathrm{oc}}(\mathrm{V})$ & $J_{\mathrm{sc}}\left(\mathrm{mA} / \mathrm{cm}^{2}\right)$ & F.F. $(\%)$ & $R_{s}(\Omega)$ & $R_{\mathrm{sh}}(\Omega)$ & $\eta(\%)$ \\
\hline $0 \mathrm{~min}$ & 0.58 & 25.07 & 55.8 & 7.4 & 995 & 8.12 \\
$5 \mathrm{~min}$ & 0.58 & 25.02 & 61.8 & 5.6 & 1023 & 8.97 \\
$10 \mathrm{~min}$ & 0.60 & 24.88 & 64.0 & 3.8 & 1087 & 9.50 \\
\hline
\end{tabular}

Before light soaking the AZO/ZnS/CIGS heterojunction solar cell generally suffered from poor one-diode behaviour, a characteristic especially marked at low temperatures. The situation is considerably improved after light soaking with various times, under AM1.5G at $100 \mathrm{~mW} / \mathrm{cm}^{2}$ illumination.
The solar cell parameters of the cells used in photovoltaic measurements in Table 1. The time needed for the parameters to saturate under illumination is also shown. Before light soaking the problem with the cells was the low fill factor and high series resistivity. The fill factor increased significantly with light soaking for $\mathrm{ZnS}$ buffer layer, while $V_{\text {oc }}$ remains stable. In Figure 5(a), $J-V$ curves obtained in the light soaked states for the lighting 5 and $10 \mathrm{~min}$.

The measurements reveal that lighting into the photoactive film results in an increase in F.F. from 55.8 to $64 \%$, but series resistivity from 7.4 to $3.8 \Omega$. The $\eta$ value of the devices improved from 8.12 to $9.50 \%$. The effect of F.F. value is attributed to the positive conduction band offsets $(\mathrm{CBO})$ between the CIGS layer and the buffer layer, and it has been suggested that this barrier is lowered by illumination due to persistent photoconductivity (PPC) in the buffer layer [15]. In this work white light-induced metastable changes to the F.F. are only observed for cells with buffer layers having a lighting time $10 \mathrm{~min}$. In addition, the quantum efficiencies are measured after light soaking in Figure 5(b). The EQE spectra are similar in shape, consistent with the almost unchanged short circuit current density.

\section{Conclusions}

In summary, the $\mathrm{ZnS} / \mathrm{CuInGaSe}{ }_{2}$ heterojunction solar cell with the light soaking process has been investigated. The crystallinity of the CIGS absorber layer is fairly good by coevaporated method. ZnS buffer layer with a band gap of $3.21 \mathrm{eV}$ was deposited on CIGS/Mo sample. The $\mathrm{MoS}_{2}$ phase

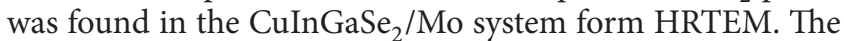
light soaking effect of photoactive film for $10 \mathrm{~min}$ results in an increase in F.F. from 55.8 to $64 \%$, but series resistivity from 7.4 to $3.8 \Omega$. The $\eta$ value of the devices improved from 8.12 to $9.50 \%$.

\section{Acknowledgment}

This research is supported by the National Science Council, Taiwan under contract no. NSC 102-3113-P-002-026.

\section{References}

[1] N. S. Lewis, "Toward cost-effective solar energy use," Science, vol. 315, no. 5813, pp. 798-801, 2007.

[2] K. L. Chopra, P. D. Paulson, and V. Dutta, "Thin-film solar cells: an overview," Progress in Photovoltaics, vol. 12, pp. 69-92, 2004.

[3] M. Konagai, "Deposition of new microcrystalline materials, $\mu \mathrm{c}$ $\mathrm{SiC}, \mu \mathrm{c}-\mathrm{GeC}$ by HWCVD and solar cell applications," Thin Solid Films, vol. 516, no. 5, pp. 490-495, 2008.

[4] L. Lu, R. Li, K. Fan, and T. Peng, "Effects of annealing conditions on the photoelectrochemical properties of dye-sensitized solar cells made with $\mathrm{ZnO}$ nanoparticles," Solar Energy, vol. 84, pp. 844-853, 2010.

[5] I. Repins, M. A. Contreras, B. Egaas et al., "19.9\%-efficient $\mathrm{ZnO} / \mathrm{CdS} / \mathrm{CuInGaSe}{ }^{2}$ solar cell with $81 \cdot 2 \%$ fill factor," Progress in Photovoltaics, vol. 16, pp. 235-239, 2008. 
[6] G. S. Chen, J. C. Yang, Y. C. Chan, L. C. Yang, and W. Huang, "Another route to fabricate single-phase chalcogenides by postselenization of $\mathrm{Cu}-\mathrm{In}-\mathrm{Ga}$ precursors sputter deposited from a single ternary target," Solar Energy Materials and Solar Cells, vol. 93, pp. 1351-1355, 2009.

[7] Y. Lai, F. Liu, Z. Zhang et al., "Cyclic voltammetry study of electrodeposition of $\mathrm{Cu}(\mathrm{In}, \mathrm{Ga}) \mathrm{Se}_{2}$ thin films," Electrochimica Acta, vol. 54, no. 11, pp. 3004-3010, 2009.

[8] S. J. Ahn, C. W. Kim, J. H. Yun et al., "CuInSe 2 (CIS) thin film solar cells by direct coating and selenization of solution precursors," Journal of Physical Chemistry C, vol. 114, no. 17, pp. 8108-8113, 2010.

[9] M. S. Hanssen, H. Efstathiadis, and P. Haldar, "Development of smooth CuInGa precursor films for $\mathrm{CuIn}_{1-X} \mathrm{Ga}_{x} \mathrm{Se}_{2}$ thin film solar cell applications," Thin Solid Films, vol. 519, no. 19, pp. 6297-6301, 2011.

[10] T. Nakada and M. Mizutani, " $18 \%$ Efficiency Cd-free $\mathrm{Cu}(\mathrm{In}, \mathrm{Ga}) \mathrm{Se}_{2}$ thin-film solar cells fabricated using chemical bath deposition (CBD)-ZnS buffer layers," Japanese Journal of Applied Physics, vol. 41, pp. L165-L167, 2002.

[11] M. Scocioreanu, M. Baibarac, I. Baltog, I. Pasuk, and T. Velula, "Photoluminescence and Raman evidence for mechanicochemical interaction of polyaniline-emeraldine base with $\mathrm{ZnS}$ in cubic and hexagonal phase," Journal of Solid State Chemistry, vol. 186, pp. 217-223, 2012.

[12] W. Chen, Z. G. Wang, Z. J. Lin, and L. Y. Lin, "Absorption and luminescence of the surface states in $\mathrm{ZnS}$ nanoparticles," Journal of Applied Physics, vol. 82, no. 6, pp. 3111-3115, 1997.

[13] X. Zhu, Z. Zhou, Y. Wang, L. Zhang, A. Li, and F. Huang, "Determining factor of $\mathrm{MoSe}_{2}$ formation in $\mathrm{Cu}(\mathrm{In}, \mathrm{Ga}) \mathrm{Se}_{2}$ solar cells," Solar Energy Materials and Solar Cells, vol. 101, pp. 57-61, 2012.

[14] D. Abou-Ras, G. Kostorz, D. Bremaud et al., "Formation and characterisation of $\mathrm{MoSe}_{2}$ for $\mathrm{Cu}(\mathrm{In}, \mathrm{Ga}) \mathrm{Se}_{2}$ based solar cells," Thin Solid Films, vol. 480-481, pp. 433-438, 2005.

[15] I. L. Eisgruber, J. E. Granata, J. R. Sites, J. Hou, and J. Kessler, "Blue-photon modification of nonstandard diode barrier in $\mathrm{CuInSe}_{2}$ solar cells," Solar Energy Materials and Solar Cells, vol. 53, no. 3-4, pp. 367-377, 1998. 

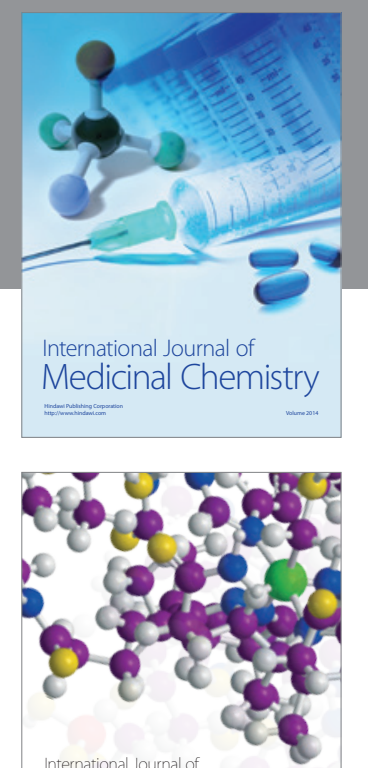

\section{Carbohydrate} Chemistry

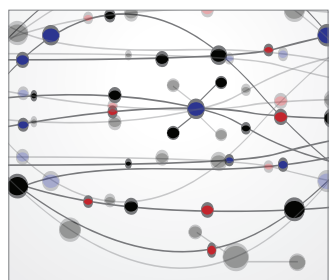

The Scientific World Journal

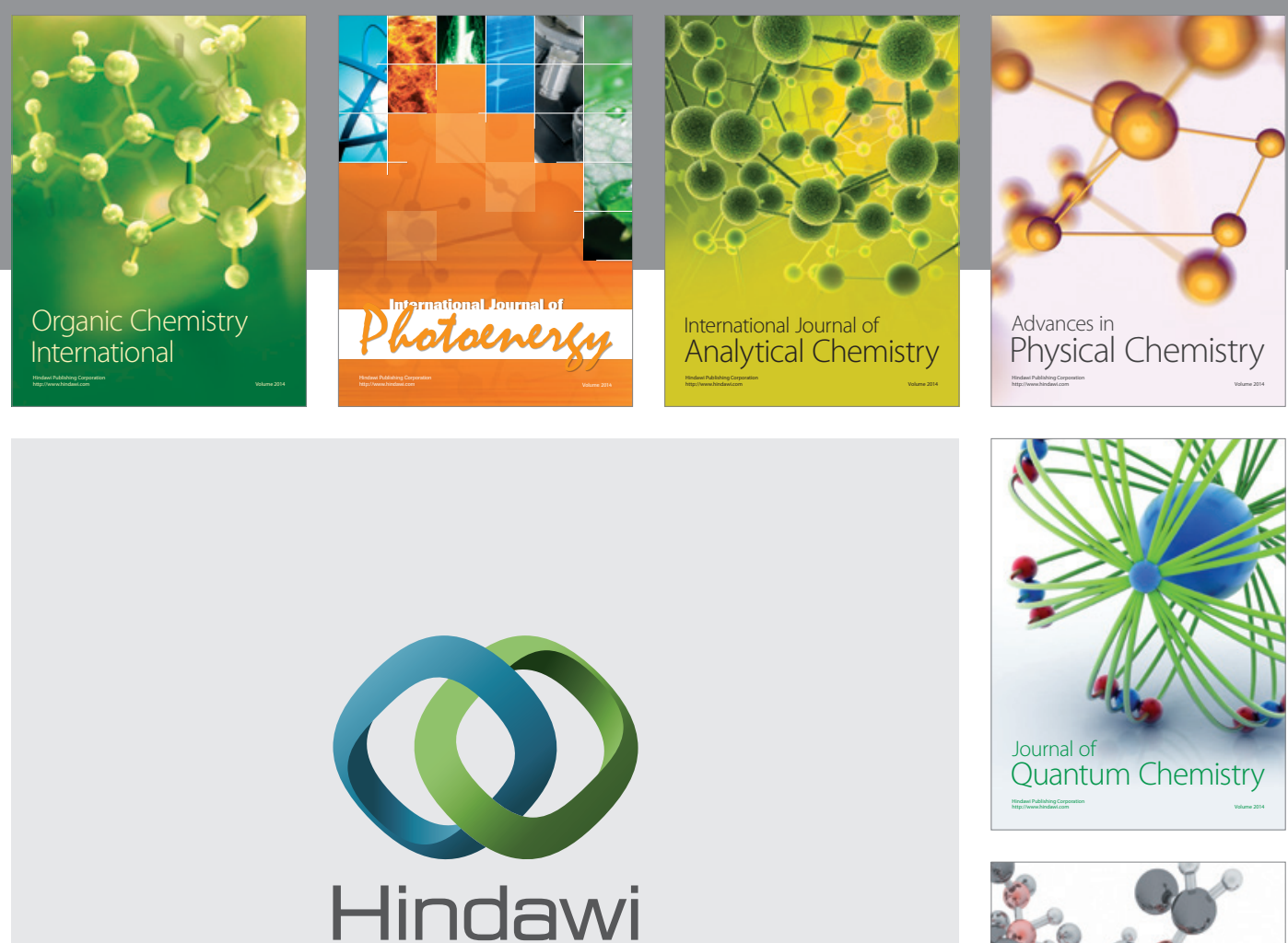

Submit your manuscripts at

http://www.hindawi.com

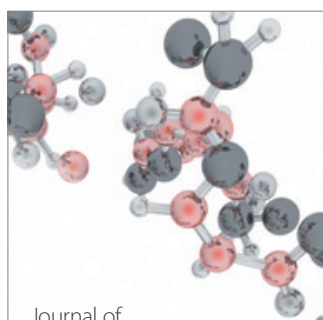

Analytical Methods

in Chemistry

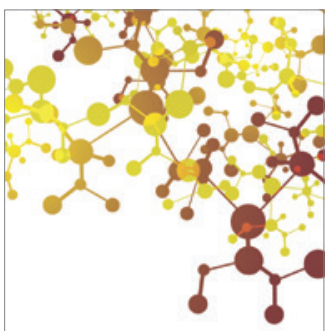

Journal of

Applied Chemistry

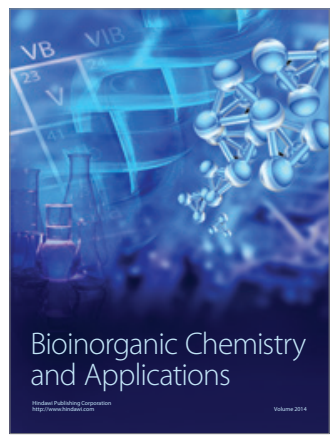

Inorganic Chemistry
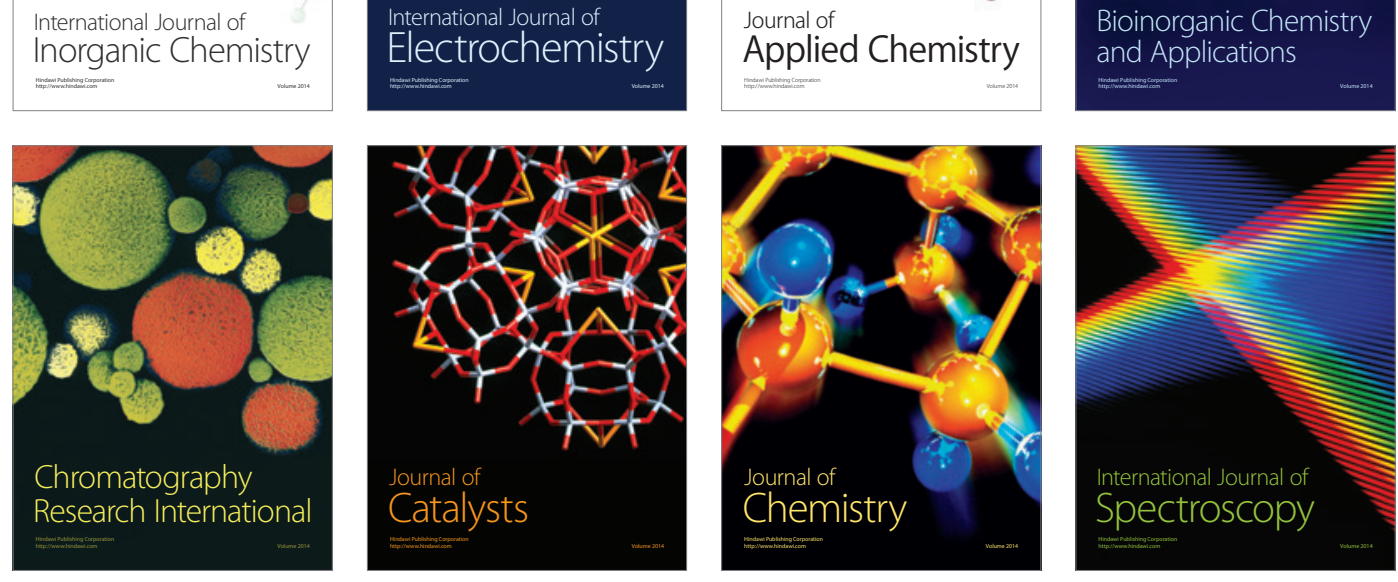